\title{
Social Status and Corruption
}

\author{
Sebastian Galiani* \\ Washington University in St. Louis \\ And \\ Federico Weinschelbaum \\ Universidad de San Andrés and CONICET
}

February 2012

\begin{abstract}
We study the interaction between social and economic incentives in determining the level of corruption. Using social rewards as incentives for civil servants may help to reduce corruption. In our model, a decrease in corruption produces an externality that reduces the cost of hiring civil servants. In particular, it makes wage schemes which avert corruption (efficiency wages) cheaper. We show that the existence of this externality reduces the "optimal" level of corruption in a society, the greater the power of social status, the lower the level of corruption.
\end{abstract}

JEL: J33, K42, D82.

Keywords: Social Status, Corruption and Wage Incentives.

\footnotetext{
* Sebastian Galiani, Professor, Department of Economics, Washington University in St. Louis, Campus Box 1208, St. Louis, MO 63130-4899, USA, galiani@wustl.edu. Federico Weinschelbaum, Universidad de San Andrés, Vito Dumas 284 (B1644BID), Victoria, Provincia de Buenos Aires, Argentina, fweinsh@udesa.edu.ar. We are thankful for the comments of two referees; Stephanie Heger, Ricardo Perez-Truglia and participants at various seminars.
} 


\section{Introduction}

Corruption is a serious problem in the developing world. Mauro (1995), for example, finds that corruption negatively affects investment in a cross-country regression analysis, thereby affecting economic development. Aidt (Forthcoming) also suggests that corruption is one of the major obstacles to sustainable development. ${ }^{1}$ It is well known that the level of corruption is greatly influenced by the system of incentives that regulates economic and political relations in the society. ${ }^{2}$ Indeed, it is typically suggested that anticorruption policies should incorporate: 1) change the legislation in order to reduce public officials rent seeking opportunities in areas prone to corrupt practices, 2) sign international anti-corruption agreements and 3) implement and integrated anti-corruption program. In spite of this, Rousso and Steves (2006), found, for example, that levels of corruption declined sharply in the former communist transition countries between 2002 and 2005. However, that reduction in corruption was not associated with anti-corruption activities such as those suggested above. Thus, it is clear that a broader analysis of the determinants of corruption, in general, and anti-corruption policies, in particular, is of much of interest.

In this paper we study the interaction between social, frequently ignored, and economic incentives in determining the level of corruption existing in a given society. Monetary and social rewards simultaneously play an important role in determining individual behavior. In particular, they interact in the determination of the corruption level of the society. We find

\footnotetext{
${ }^{1}$ In the world International Anti-Corruption Day, December 9 2011, UN Secretary-General Ban $\mathrm{Ki}$-moon has called on all individuals to act against the cancer of corruption. United Nation Office for Drugs and Crime Executive Director Yury Fedotov started his statement saying that: "Corruption is a global phenomenon that impedes development and promotes inequality and injustice." Also other International institutions such as the World Bank and the International Monetary Fund are giving increasingly importance to corruption issues in developing countries.

${ }^{2}$ See Banerjee, Hanna and Mulainathan (Forthcoming) for a recent review of the economic literature on corruption.
} 
that, incorporating nonmonetary rewards into the analysis, combating corruption improves government finances not only through its direct effect, but also because it allows the government to pay lower wages, since inspectors will be getting higher payments in the form of social-status rewards.

We view social status as a substitute for money, in line with the long-standing theory of compensating wage differences. Thus, high-status occupations would pay lower wages, ceteris paribus. As noted in Weiss and Fershtman (1998), this was already suggested by Adam Smith: "Honor makes a great part of the reward of all honorable professions. In point of pecuniary gain, all things considered, they are generally under-compensated... The most detestable of all employment, that of public executioner, is, in proportion to the work done, better paid than any common trade whatever" (The Wealth of Nations, Book I, ch. X, part i).

We center our attention on a particular case of corruption: collusion between tax collectors and taxpayers to evade taxes. We build upon the interesting model developed by Besley and McLaren (1993), which evaluates alternative payment schemes for tax inspectors in the presence of the threat of corruption. In this setup, there are problems of both moral hazard (because the acceptance of bribes cannot be monitored without a costly surveillance system) and adverse selection (since inspectors cannot be individually identified as being honest or dishonest). We depart from Besley and McLaren (1993) by assuming that a mix of private and social rewards is used by society as incentives for tax collectors. Individuals derive utility both from money and social status. A person may gain social status in several ways. In this paper, we follow Fershtman and Weiss (1993) in assuming that social status is conferred through occupational association. 
In particular, we assume that the social status of tax collectors varies inversely to the rest of society's perception of corruption in this group. Thus, it is assumed that social status of the tax collectors is determined by their average level of honesty as perceived by society (since we also assume that whether or not each civil servant behaves honestly is not known). The emphasis on the perceptions of society is not arbitrary. Social status rests on collective judgment or, rather, on a consensus of opinion within a group. No one person, acting alone, can confer status on another, and if everybody whom a given individual meets were to assess that individual's social position differently, then the person's social status would be entirely indeterminate (Marshall, 1977).

In this sense, social status could also be called "collective reputation" as in Tirole (1996). Tirole's work concentrates on the dynamics of "collective reputation" and how it interacts with reputation at the individual level while our paper studies the effects of social status in the optimal monetary payment scheme and the level of corruption.

Certainly, there are a number of other authors who put more emphasis on individual deeds or characteristics as a source of social status. ${ }^{3}$ These two views imply different types of externalities, however (see Fershtman and Weiss, 1993). In our model, if a civil servant behaves honestly, the status of the group increases, and that civil servant's conduct therefore makes a positive contribution to all workers in the profession. In contrast, if social status were influenced by one's relative standing in a group, and if the degree of honesty of each individual's form of behavior were observable - which, certainly, is not realistic- then a civil servant who behaves honestly might confer a negative externality on his or her colleagues (see also Basu, 1989). 
More generally, it has been recognized in the literature that activities that affect other members of society but that cannot be priced are not efficiently regulated by private rewards. It was Arrow (1971) who first suggested the role of social norms as a mechanism for resolving the inefficiencies arising from externalities. In this paper, we consider a similar role for social status in regulating the level of corruption in tax collection (see also Fershtman and Weiss, 1998).

In this paper we show that if a society uses social rewards to provide incentives for civil servants, then the "optimal" level of corruption, ceteris paribus, will be lower than it would be in a society where social status is unnoticed. This holds true because, in societies that coordinate their efforts to use social rewards to provide incentives for civil servants, payment schemes that prevent corruption will be less expensive (since part of the payment is made through social status) and payment schemes that induce high levels of corruption will be more expensive than they would be in societies that do not have recourse to social rewards. Thus, there are more economies (i.e., parameter values) for which payment schemes that deter corruption are implemented. Ignoring social rewards could lead to obtain wrong conclusions and implement erroneous policies.

The rest of this paper is organized as follows. In Section II, we present our model, which is based on Besley and McLaren (1993). In Section III, we describe the different payment schemes: (a) reservation wages, (b) efficiency wages and (c) capitulation wages. We then present our main results in Section IV and our conclusions in Section V.

\footnotetext{
${ }^{3}$ Auriol and Renault (2008), for example, study the use of status levels of individual employees within an organization as a source of incentives.
} 


\section{A Simple Model}

We focus on the interplay of social and economic incentives and how it influences the level of corruption. In this section we will develop a simple model to illustrate the main points of interest in this regard. We adopt the setup of Besley and McLaren (1993) in studying alternative payment schemes for civil servants in the presence of corruption but depart from them by assuming that individuals also value the social status attached to the occupation they choose. Following Fershtman and Weiss (1993), we assume that individuals obtain part of their reward in the form of social status and part of it as earnings, which include the wage paid by the government and, under dishonest behavior, also the bribes collected. In particular, we assume that civil servants' social status depends on the social reputation of the government agency that employs them. We recognize that the quest for social status is an important factor in the allocation of workers to different occupations. Thus, we assume that social status is part of the reward scheme for economic agents. Social status is often gained by association with a particular group and is shared by all members of the group, regardless of their individual characteristics. This collective good aspect implies that the actions or traits of each member in a status group will influence the social status of all other members of the group. In particular, we assume that the static utility function of inspectors is given by:

$$
\mathrm{U}_{\mathrm{it}}=\mathrm{e}_{\mathrm{t}}+\mathrm{s}_{\mathrm{t}}
$$

where $e_{t}$ is the earnings received in period $t$ and $s_{t}$ is the social status obtained from working as an inspector. Meanwhile, the static utility derived from working in the private sector is 
equal to the earnings in that sector $(\omega)$. Individuals maximize their discounted expected utility and, for simplicity, we assume that they live forever. The value of $s_{t}$ depends on the social reputation of the tax office. We assume it varies inversely to the current level of corruption in tax collection. Thus, when corruption is high, social status is low and may possibly take a negative value (i.e., an inspector has to receive earnings higher than his or her opportunity cost in order to compensate him or her for the disutility of being perceived as a corrupt citizen). In contrast, when corruption is low, social status is high.

Similarly to Besley and McLaren (1993), we assume that the government requires a continuum of size $N$ of tax inspectors to service a continuum population of size $M$ of potential taxpayers. Only a proportion $\theta$ of these potential taxpayers must pay a tax $\tau$, while the rest owe no tax. The government is assumed to know the proportion $\theta$, but it does not know how honest or dishonest each inspector is. There are two types of potential tax inspectors in the population: A proportion $\gamma_{\text {of }}$ them are dishonest, while the rest are honest. Dishonest inspectors may take bribes, while honest inspectors do not take any material reward as a bribe. Dishonesty is an immutable characteristic of preferences. Each inspector faces the same opportunity cost $\omega$. In each period, tax inspectors and taxpayers are randomly matched. When the taxpayer must pay a tax $\tau$ (an event that occurs with probability $\theta$ ), an honest inspector collects the tax and hands over the revenues to the government, while a dishonest inspector may offer the taxpayer the chance to pay a bribe $b<\tau$, which here we take as a given. ${ }^{4}$ We call $\mathrm{D}$ to the number of inspectors who behave dishonestly, which may differ from the number of intrinsically dishonest inspectors. Tax inspectors are audited with exogenous probability (1-q), and if they are caught behaving dishonestly, they are fired but 
not fined. Similarly, taxpayers who are found to have paid bribes are simply required to pay the taxes which they evaded, but no fines are levied on them. Finally, at the beginning of each period there is a random turnover of tax inspectors at constant rate $\delta$. Tax inspectors come from a large population and are homogeneous in their discount factor $p$.

We assume that the status payment is given by:

$$
s_{t}=m\left(\alpha-\frac{D_{t} q}{N}\right)
$$

where $D q / N$ represents the government tax obligations that are evaded (as a fraction of the total government tax obligations) ${ }^{6}$ and where $1>\alpha>0$ is a standard normalization. When $\alpha$ $\geq q$, inspectors always receive a positive social reward, while when $\alpha=0$, inspectors are always socially punished. It is unlikely, then, that $\alpha \geq q$, since this would imply that, even when all inspectors are dishonest, society will reward this group positively. Finally, $m>0$ indicates the power of social status in terms of the total reward of inspectors (Besley and McLaren (1993) can be interpreted as implicitly assuming $m=0) .^{7}$ Thus, we are implicitly assuming that there is a wage premium that workers are willing to give up for working in an agency with a higher level of social status (i.e. lower level of corruption).

\footnotetext{
${ }^{4}$ Besley and McLaren (1993) derive the size of the bribe $b$ as a result of a Nash bargaining solution between the inspector and the taxpayer.

${ }^{5}$ Most of our results are robust to more general utility functions. We adopted this functional form in order to preserve the simplicity of the model.

${ }^{6}$ All our results are robust to incorporating the proportion of detected corrupt agents as an argument of the social status function.

${ }^{7}$ We take the power of social status $(m)$ as being exogenous. Kaplow and Shavell (2007) examine the way in which societies may choose how to set moral sanctions and rewards in order to maximize social welfare.
} 


\section{III.Economic Incentives}

As in Besley and McLaren (1993), we now solve the model under three possible wage strategies: (1) reservation wages, where the government pays a wage that induces honest inspectors to accept the job, in equilibrium, both types of inspectors are hired, but the dishonest ones behave corruptly; (2) efficiency wages, where the government pays a wage premium that makes dishonest inspectors indifferent between behaving honestly and corruptly, in equilibrium, both types of inspectors are hired but nobody behaves dishonestly; and (3) capitulation wages, where the government pays the lowest wage at which dishonest inspectors accept the job, in equilibrium, only dishonest inspectors accept the job and proceed to behave dishonestly.

\section{A. Reservation Wages}

The reservation wage is the wage level that induces honest inspectors to accept the job. When there are no social status payments (i.e., $m=0$ ), the reservation wage is exactly equal to the opportunity cost $(\omega)$ of tax inspectors in the private sector, while in a society that also uses social status to reward individuals (i.e., $m>0$ ), the reservation wage $\left(w^{R}\right)$ has to compensate for that opportunity cost minus the social reward associated with the job:

$$
w^{R}=\omega-m(\alpha-D q \theta / N \theta)
$$

Under this payment scheme, honest inspectors behave honestly and dishonest inspectors behave dishonestly. Thus, the social status level that workers get depends on the proportion of honest and dishonest inspectors. The quantity of dishonest inspectors in each period is composed by the dishonest inspectors that survive, which constitutes the first term 
in the following difference equation, by the dishonest inspectors that replace the inspectors that go out of the agency at the beginning of each period through a random turnover, which constitutes the second term and by the dishonest inspectors that replace the inspector that are caught behaving dishonestly, which constitute the third term in the following equation:

$$
D_{t+1}=(1-\delta)[1-\theta(1-q)] D_{t}+\delta N \gamma+(1-\delta) \theta(1-q) \gamma D_{t}
$$

This expression can be rewritten as follows:

$$
D_{t+1}=(1-\delta)[1-\theta(1-q)(1-\gamma)] D_{t}+\delta N \gamma
$$

Thus, the steady state number of dishonest inspectors is given by: ${ }^{8}$

$$
D=\frac{\gamma N \delta}{1-(1-\delta)(1-\theta(1-q)(1-\gamma))}
$$

and the lowest wage at which honest inspectors accept the job, given that the dishonest inspectors behave corruptly, is:

$$
w^{R}=\varpi-m\left(\alpha-\frac{q \gamma \delta}{1-(1-\delta)(1-\theta(1-q)(1-\gamma))}\right)
$$

Note that this wage is higher (lower) than the opportunity cost $(\omega)$ of the agents depending on whether $\alpha$ is smaller (higher) than the steady-state percentage of government tax obligations being evaded. The parameter $\alpha$ could be considered as a fixed factor that includes all the other features (except corruption) that account for the social rewards

\footnotetext{
${ }^{8}$ Note that the steady state proportion of dishonest inspectors is lower than the proportion of dishonest inspectors in the population. This is because, on average, each honest inspector subsists longer than a dishonest one in the tax office.
} 
received by tax inspectors. The steady-state percentage of evaded tax payments depends positively on the percentage of dishonest inspectors, on the discount factor and on the probability of no inspection (q).

\section{B. Efficiency Wages}

The efficiency wage is defined as the wage level that induces inspectors to behave honestly regardless of whether they are honest or dishonest. Under this payment scheme there are no inspectors who behave dishonestly (i.e. $\mathrm{D}=0$ ), and being a civil servant then conveys positive social status that increases tax inspectors' utility. In order to compute the efficiency wage $\left(w^{E}\right)$ of this economy, we equate the lifetime utility of a dishonest inspector who behaves honestly to the inspector's lifetime utility when she or he behaves dishonestly. We obtain:

$$
w^{E}=\varpi-m \alpha+q b \frac{p+\delta}{(1-q)(1-\delta)}
$$

Social rewards reduce the fiscal cost of encouraging inspectors to behave honestly. In a world without social rewards in which inspectors consequently receive no status premium, the efficiency wage equals the opportunity cost of inspectors in the private sector plus the premium needed to provide incentives that will cause dishonest inspectors to behave honestly. Note that, under this payment scheme, all honest and dishonest inspectors will behave honestly. Thus, the steady state number of dishonest inspectors is irrelevant.

\section{Capitulation Wages}


The capitulation wage is the lowest wage at which dishonest inspectors would accept the job. We assume that all dishonest inspectors will behave corruptly. To compute the capitulation wage $\left(w^{C}\right)$, we equate the lifetime utility of potential inspectors who choose to work in the private sector instead to their lifetime utility if they accept a job as an inspector. We obtain:

$$
w^{C}=\varpi-\theta q b-m(\alpha-q)
$$

Note that, under this payment scheme, all inspectors will be dishonest and will behave dishonestly.

In this case, the social status attached to being a civil servant achieves its minimal value. When $\alpha<q$, an inspector needs to be paid a premium to compensate for the social punishment associated with being part of a corrupt government. The converse would be true if $\alpha>q$, although such a case seems to be extremely unlikely. 


\section{Results}

Since Besley and McLaren (1993) do not consider social status as an incentive for tax collectors, their comparison differs from ours. Their comparison is orderly. For any given value of the parameters that define an economy, the capitulation wage will always be lower than the reservation wage, which in turn will always be lower than the efficiency wage. This means that, for a given wage, it is easy to establish the types of individuals who would choose to work in the public sector as tax collectors and their equilibrium behavior. Figure 1 illustrates these features of the Besley and McLaren (1993) model.

Figure 1: Behavior of workers in BML

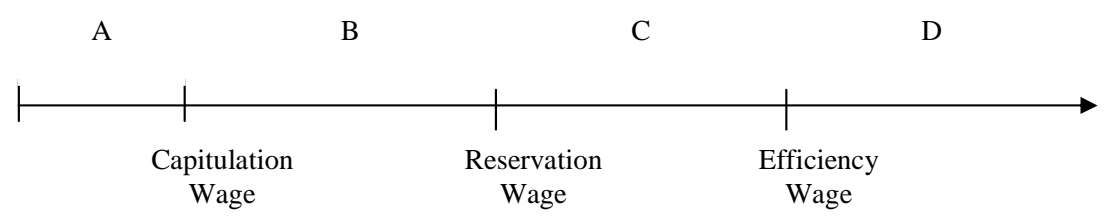

Four areas are clearly defined in Figure I. In Area A, where wages are below the capitulation wage, there are no individuals willing to work in the public sector as tax collectors. In Area B, where wages are above the capitulation wage but below the reservation wage, only dishonest individuals would agree to work as tax collectors, and all of them would behave dishonestly. In Area $\mathrm{C}$, where wages are between the reservation wage and the efficiency wage, both types of individuals would agree to work as inspectors, and dishonest workers would behave corruptly under the prevailing wage in this area. Finally, in Area D, where the wage is above the efficiency wage, both types of individuals would agree to work as tax collectors and would behave honestly. These results change considerably in the case of 
a society that also coordinates its efforts to use social rewards to provide incentives for civil servants.

First, let us consider the case in which social punishment is slight (i.e., small $m$ ). There are values for $m$ such that the ranking of economic incentives is unaltered (i.e., capitulation wage $<$ reservation wage $<$ efficiency wage). However, even for small values of $m$ such that the ranking of wages is preserved, the behavior of tax collectors may change in equilibrium. One instance of such a situation is the following: For wages in the right neighborhood of the reservation wage given by equation 1 , there are two possible compositions of inspectors. In one both honest and dishonest inspectors coexist in the tax collection agency; while in the other, only dishonest individuals accept jobs as tax collectors. In this latter case, honest individuals do not agree to work as tax collectors because, at the given wage, the social status associated with the job provides too low a level of compensation. In other words, the proportion of corrupt inspectors is too high to attract honest people to the job.

Second, let us consider the opposite case (i.e., $m$ is big enough) as, in fact, there are large enough values of $m$ such that the ranking of economic incentives is reversed:?

$$
\text { Capitulation Wage }\left(w^{C}\right)>\text { Reservation Wage }\left(w^{R}\right)>\text { Efficiency Wage }\left(w^{E}\right)
$$

In this case, the social status associated with the position of a tax collector in the public sector is so high that dishonest inspectors have incentives to behave honestly in order to increase the probability of continuing in their jobs even though wages are low. In contrast,

\footnotetext{
${ }^{9}$ This result follows because the derivatives of the three wages with respect to $m$ are constant and $\frac{d\left(w^{C}\right)}{d m}>\frac{d\left(w^{R}\right)}{d m}>\frac{d\left(w^{E}\right)}{d m}$.
} 
when all the inspectors behave dishonestly, wages have to be extremely high to offset the social stigma associated with the job.

In this case as well, at a given wage, different situations are possible, some of which could resemble the conditions outlined in the literature on corruption with multiple equilibria (see, among others, Tirole, 1996). However, this is not exactly the case, since in our environment, in order to be at equilibrium, wages need to be set at an optimal level. Instead, what we have are different configurations at a given wage. The government would use other instruments or even use the dynamics of the system to choose the least expensive way to arrive at an optimal wage scheme. Under these circumstances, a political shake-up or purge, in which the entire pool of civil servants (or politicians) is fired at once, could be interpreted as an instrument for switching from an unsatisfactory configuration of tax collectors to a better one. ${ }^{10}$

We now provide a set of general results for economies that rely on both social and economic rewards as incentives for civil servants. We start by remarking that whenever honest people are willing to work as inspectors; dishonest ones will also accept the job. This follows from the fact that the outside opportunity cost is the same for both types of individuals, and the utility of a dishonest inspector is always higher than or equal to the utility of an honest individual, since a dishonest person can always mimic an honest individual and obtain that person's level of utility. This implies that there are always dishonest inspectors in the civil service although they do not necessarily always behave dishonestly.

${ }^{10}$ In Argentina during the 2001-2002 economic crisis, the people took to the streets to demand a political purge. Their demand was: "Que se vayan todos" ("All of them must go"). Our model provides a rationalization for this popular demand. 
Let us now define the real efficiency wage $\left(w^{\mathrm{RE}}\right)$ as the lowest wage that induces all inspectors to behave honestly, independently of the behavior of the other inspectors. In our model, this is given by:

$$
w^{R E}=\varpi-m(\alpha-q)+q b \frac{p+\delta}{(1-q)(1-\delta)}
$$

The real efficiency wage is the wage at which dishonest tax collectors are willing to behave honestly even when all other inspectors are behaving dishonestly. As can be seen, the real efficiency wage is higher than the other three payment schemes considered previously (i.e., capitulation wages, reservation wages and efficiency wages). ${ }^{11}$ Whenever the prevailing wage in the public sector is higher than the real efficiency wage, there will be a unique configuration in which both types of individuals work as tax collectors and both will behave honestly. Once the level of corruption is reduced (i.e. the level of social status is raised) the government could reduce the wages -to a minimum of $w=\varpi-m \alpha+q b \frac{p+\delta}{(1-q)(1-\delta)}$ (i.e., the earlier "efficiency wage")- without changing neither the behavior of the dishonest inspectors nor the incentives of honest ones to accept the job. ${ }^{12}$

Economies can differ in many ways. Here, we are interested in the effects, in terms of corruption, of the heterogeneity of the power of social status in relation to the total rewards received by inspectors.

\footnotetext{
${ }^{11}$ When status is a premium $(\alpha>q)$, the real efficiency wage is lower than the efficiency wage of Besley and McLaren (1993). But when $(\alpha<q)$, as we expect it to be, then the real efficiency wage is higher than the Besley and McLaren (1993) efficiency wage.

${ }^{12}$ Note that efficiency wages are lower than they are under Besley and McLaren (1993) because some of the corresponding incentives are "paid for" by the status effect.
} 
We define the average (across economies) percentage of taxes evaded as follows:

$$
\sum_{w_{i}} P\left(w_{i}=w^{*}\right) x \operatorname{Evasion}\left(w_{i}\right)
$$

where $w^{*}$ is the optimal payment scheme, $w_{i} \varepsilon\left\{w^{E}, w^{R}, w^{C}\right\} ; P\left(w_{i}=w^{*}\right)$ is the probability (across economies) that wage scheme $w_{i}$ is the optimal payment scheme and Evasion( $\left.w_{i}\right)$ is the percentage of tax evasion that takes place under wage scheme $w_{i}$

Assuming that societies will choose the payment scheme that maximizes net revenues, and holding all other characteristics constant, we obtain the following result:

Proposition 1: The average percentage of tax that is evaded (across economies), which is a measure of the amount of corruption that exists, decreases as the power of social status as a contributing factor to the rewards received by inspectors $(m)$ increases.

Proof: see the Appendix.

The intuition is simple: The power of social status in rewarding inspectors makes it easier to motivate inspectors to behave honestly and harder to hire inspectors to work in a corrupt agency. Thus, the set of economies (parameter values) in which efficiency wages (capitulation wages) are used is larger (smaller). The status effect complements other incentives for behaving honestly and increases the costs of maintaining a corrupt agency.

Thus, societies in which social status is more important will be, on average, less corrupt. We take the value that societies give to social status as exogenous. If we would allow this value to be endogenous (as in Kaplow, L. and S. Shavell (2007)), we would find that, inducing the importance of social status, for example, through education of the population would help to reduce the level of corruption. 


\section{Conclusions}

In studying the effects of social-status rewards in terms of the payment of workers, we find that the optimal payment scheme and the amount of evasion associated with it depend on how powerful social-status rewards are. A failure to analyze the significance of socialstatus rewards may result in erroneous conclusions and thus could lead to the use of incorrect policies.

Combating corruption improves government finances not only because of the increase in revenues brought about through its direct effect, but also because it allows the government to pay lower wages, since inspectors will be getting higher payments in the form of social-status rewards. The status effect complements the use of efficiency wages, since at least part of the wage premium is "paid" by social rewards. In contrast, if capitulation wages are used, workers will need to receive a higher payment in order to compensate them for the negative status effect.

Social incentives introduce the possibility of having, for the same wage level, different configurations of population and/or behavior of tax inspectors. Thus, a possible policy for reducing corruption is a purge (or raziaas), in which the entire pool of civil servants (or politicians) is fired at once, as an instrument for switching from an unsatisfactory configuration of tax collectors to a better one. Another possible policy against corruption is to raise wages to such a level in which there is no corruption. Once the level of corruption is reduced, and the social status is raised, the government could reduce wages, substituting monetary wages by social incentives, without changing the level of corruption.

Finally, societies in which social-status rewards are powerful will tend to have less corruption because they will use efficiency wages more frequently and capitulation wages less 
frequently. Thus, inducing the importance of social status would lead to reduce the level of corruption. 


\section{References}

Aidt, T.S. Forthcoming "Corruption and Sustainable Development" prepared for RoseAckerman, S and T.Søreide (ed) International Handbook on the Economics of Corruption, Volume 2, Edwar Elgar, Northampton, MA, USA.

Auriol, E. and R. Renault (2008): "Status and Incentives", The RAND Journal of Economics, vol. 39, n. 1, Spring, pp. 305-326.

Arrow, K. J. (1971): "Political and economic evaluation of social effects and externalities", in Intriligator, M. (ed.), Frontier of Quantitative Economics, North Holland, Amsterdam.

Banerjee,A, R. Hanna and S. Mullainathan. Forthcoming "Corruption" prepared for Gibbons R, and J.Roberts (ed) Handbook of Organizational Economics, Princeton University Press, Princeton, NJ, USA.

Basu, K. (1989): “A Theory of Association: Social Status, Prices and Markets”, Oxford Economic Papers, vol. 41, Issue 4, pp. 653-671.

Besley, T. and J. McLaren (1993): "Taxes and Bribery: The Role of Wage Incentives", The Economic Journal, vol. 103, No. 416, pp. 119-141.

Fershtman, C. and Y. Weiss (1993): "Social Status, Culture and Economic Performance", The Economic Journal, vol. 103, No. 419, pp. 946-959.

Fershtman, C. and Y. Weiss (1998): "Social Rewards, Externalities and Stable Preferences", Journal of Public Economics, vol. 70, pp. 53-73.

Kaplow, L. and S. Shavell (2001): "Moral Rules and the Moral Sentiments, and Behavior: Toward a Theory of an Optimal Moral System", Journal of Political Economy, vol. 115, pp. 494-514.

Marshall, A. (1890): Principles of Economics, reprinted, Macmillan, London, 1962.

Mauro, P. (1995) “Corruption and Growth" Quarterly Journal of Economics vol 110, pp 681-712.

Rousso, A. and F.Steves (2006) "The Effectiviness of Anti-corruption Programs: Preliminary Evidence from the Post-communist Transition Countries", in Rose-Ackerman, R. (ed). International Handbook on the Economics of Corruption, Volume 1, Edwar Elgar, Northampton, MA, USA.

Smith, A (1976): The Wealth of Nations, reprinted, Modern Library, New York, 1937.

Tirole, J. (1996): “A Theory of Collective Reputations (with Applications to the Persistence of Corruption and to Firm Quality)" Review of Economic Studies, vol. 63, No. 1, pp. 1-22. 
Weiss, Y. and C. Fershtman (1998): "Social Status and Economic Performance: A Survey", European Economic Review, vol. 42, Issues 3-5, pp. 801-820. 


\section{Appendix \\ Proof of Proposition1}

We know that:

$\operatorname{Evasion}\left(w^{E}\right)=0$

$\operatorname{Evasion}\left(w^{R}\right)=\frac{q \gamma \delta}{1-(1-\delta)(1-\theta(1-q)(1-\gamma))}$

$\operatorname{Evasion}\left(w^{C}\right)=q$

so,

$\operatorname{Evasion}\left(w^{C}\right)>\operatorname{Evasion}\left(w^{R}\right)>\operatorname{Evasion}\left(w^{E}\right)$

Thus, the amount of evasion that occurs under each payment scheme does not depend on $m$ (the power of social status in rewarding inspectors); instead, changes in the amount of evasion are determined solely by changes in the probability of using different payment schemes. The fact that total tax collection is independent of $m$ and $\frac{d\left(w^{C}\right)}{d m}>\frac{d\left(w^{R}\right)}{d m}>\frac{d\left(w^{E}\right)}{d m}$ imply that, when the power of social status is greater, there will be more economies (parameter values) where efficiency wages are optimal and fewer economies where capitulation wages are optimal. This completes our proof. 